\title{
Impactos da desvalorização do real sobre o comércio entre o Brasil e a Argentina
}

\section{JORGE HUGO HERRERA VEGAS*}

Antes de começar a discorrer sobre a evolução do comércio bilateral e o seu futuro, a partir da desvalorização da moeda brasileira no início de 1999 e da depreciação ocorrida depois da flutuação neste ano, é importante tratar de entender os porquês dessa desvalorização.

Depois, analisarei a influência do tipo de câmbio real e o nível de atividade econômica no comércio entre os dois países, assim como sua evolução desde a assinatura do Tratado de Assunção até a desvalorização de janeiro e, finalmente, tratarei de realizar alguma análise do comércio para o futuro.

\section{Os tratados de Assunção e Maastricht}

Como se sabe, as normas básicas do Mercosul estão contidas no Tratado de Assunção de 1991.

O que não é tão conhecido é que esse tratado, como marco do início de uma união aduaneira e um mercado comum, previa outros objetivos adicionais ao cronograma de redução tarifária que é o aspecto mais conhecido do Mercosul.

Dentro deles e em primeiro grau de importância, o artigo $1^{\circ}$ do Tratado fixou como objetivo inter alia "a coordenação de políticas macroeconômicas e setoriais...".

A tal efeito, foi criado um Subgrupo de Trabalho de Coordenação de Políticas Macroeconômicas dentro da estrutura de funcionamento do Grupo Mercado Comum. Devo salientar que, depois da assinatura do Protocolo de Ouro Preto em 1994, esse Subgrupo de Trabalho perdeu seu caráter específico e a coordenação macro deixou de ser o objetivo exclusivo de um grupo de trabalho. Esta modificação foi realizada a partir de um pedido do Brasil - que se encontrava implementando a transição para o Plano Real - e teria tido a contrapartida da promessa de não se realizar "desvalorizações competitivas" que pudessem prejudicar os seus parceiros comerciais dentro do Mercosul ${ }^{1}$. 
Devo destacar que não foi este o único ponto do Tratado de Assunção que não foi posto em prática, senão que boa parte das suas cláusulas não foi ainda implementada e isto não é responsabilidade só do Brasil, porém de todos os sócios.

Mas, voltemos ao ponto central. Por que é tão importante a coordenação de políticas macroeconômicas dentro da união aduaneira?

Essa coordenação procura:

- primeiro, facilitar os fluxos comerciais entre os países, mantendo um tipo de câmbio real estável entre eles;

- segundo, guiar para a concessão dos recursos produtivos e da localização dos investimentos, conforme critérios de vantagens comparativas e competitivas dentro da zona de integração;

- terceiro, contribuir a orientar àqueles que, no setor privado, tomam as decisões no âmbito do comércio e dos investimentos.

A redução tarifária realizou-se entre 1991 e 1994 sem nenhum tipo de coordenação macroeconômica e com importantes déficits da balança comercial para a Argentina. A partir de julho de 1994, em que começou a etapa preparatória do Plano Real, a moeda brasileira valorizou-se sensivelmente em relação ao dólar e, em conseqüência, ao peso argentino. A manutenção de um tipo de câmbio estável por um prazo de tempo prolongado fez com que os propósitos da coordenação macro, de fato, fossem atingidos pelo menos parcialmente.

Porém, a falta de uma coordenação explícita tem custos importantes a curto e longo prazos, ao gerar incerteza nos agentes econômicos. Mas o fato certo é que, por diferentes motivos, não se cumpriu o estabelecido no artigo $1^{\circ}$ do Tratado de Assunção.

Essa situação foi reconhecida pelos Presidentes Menem e Cardoso em sua reunião de 7 de junho último em Buenos Aires, quando, pela primeira vez, mencionou-se a necessidade de um pequeno Maastricht, tratado que deu origem à criação do euro e obrigou ao cumprimento de determinados objetivos macroeconômicos por parte dos países membros da União Européia, como requisito de sua participação na moeda comunitária. Nessa oportunidade, os Presidentes instruíram seus ministros das áreas respectivas a fim de ativarem as tarefas relacionadas com essa coordenação.

A tal respeito, algo para pensar. Paul Krugman, em seu brilhante livro Peddling prosperity, manifesta que um dos possíveis motivos pelo qual as autoridades européias teriam aceitado ceder sua soberania monetária foi o reconhecimento de que a forma de minimizar os custos políticos internos em cada país pela realização dos necessários processos de ajuste tendentes a conseguir determinados equilíbrios macroeconômicos era que uma autoridade supranacional impusesse esses critérios.

Parece-me que é politicamente mais aceitável exigir disciplina fiscal com base em compromissos realizados no âmbito do Mercosul que a partir de exigências do FMI. 
Acredito que, nos próximos anos, veremos crescentes avanços na coordenação macroeconômica, ainda que, devemos recordar, esta seja uma tarefa para o longo prazo.

Entrando no tratamento das desvalorizações dentro do Mercosul, os impactos da desvalorização do real têm sido sentidos de forma importante por todos os parceiros, tanto por seus efeitos na economia real quanto nos fluxos financeiros.

Deve salientar-se que, à diferença da União Européia, o tamanho relativo das economias principais do Mercosul difere consideravelmente. Como exemplo, a dimensão da economia do Brasil é quase o triplo da da Argentina. A dimensão da economia da Alemanha é só 30\% maior que a da França.

Isto leva, necessariamente, a admitir que uma mudança macroeconômica relevante, crescimento ou recessão, desvalorização ou sobrevalorização da moeda no Brasil, tem um impacto maior em seus parceiros do que qualquer fato de características semelhantes nos outros três membros do bloco.

Se isto for assim, caberia perguntarmo-nos, como acontece em círculos acadêmicos na Argentina, no Uruguai, no Paraguai e também no Brasil, em particular na PUC - Rio, se não corresponderia algum tipo de compensação nesse sentido.

Simultaneamente, e para sermos equânimes, poderíamos também perguntarmo-nos por alguma compensação com relação à sobrevalorização da moeda brasileira particularmente no período 95-97.

Deve destacar-se que, no modelo de união aduaneira europeu, quando existiram desvalorizações, inclusive dentro do sistema monetário europeu, não existiram compensações. Porém, a moeda única faz com que estes fatos não possam produzir-se no futuro e com que os processos de ajuste do setor externo das economias devam realizar-se através da política fiscal. De forma adicional, quero salientar que a fixação da paridade entre as moedas para ingressar na moeda única foi realizada pelo mercado.

Voltando ao Mercosul, acredito que, na realidade, neste momento, o mal já foi feito e a tolerância às restrições ao mercado por acordos entre produtores dos diferentes países permitirá, a curto prazo, compensar boa parte dos efeitos mais danosos da desvalorização, em particular na Argentina.

Estes comentários tendem a induzir à reflexão sobre a necessidade de uma convergência de metas macroeconômicas. O episódio final dessa convergência poderia ser a moeda comum e ela evitaria este tipo de problemas, mas, enquanto isso não é atingido, deveremos imaginar soluções aos eventuais problemas antes que eles aconteçam.

O Mercosul é um projeto com implicações políticas e estratégicas que excedem a dimensão econômica e comercial e é necessário que as perturbações nessas áreas não o coloquem em perigo. 
Para avançar sobre o propósito deste texto, parece-me importante lembrar quais são os objetivos buscados por uma desvalorização e quais são suas conseqüências sobre a economia.

Quando a autoridade econômica decide desvalorizar a moeda é porque considera que está enfrentando desequilíbrios na balança de pagamentos que transformam em insustentável um determinado tipo de câmbio, já que as reservas diminuíram a um nível que se considera inaceitável.

A teoria econômica, na sua versão mais simples, indica que uma desvalorização tem o objetivo de mudar o set de preços relativos da economia, transformando em mais caros os produtos importados e melhorando a competitividade relativa dos produtos nacionais por uma diminuição do valor em moeda estrangeira dos bens e serviços nacionais vis-à-vis dos importados no mercado interno, e nos mercados externos. Ou seja, teoricamente, deveríamos observar uma importante melhoria na conta corrente da balança de pagamentos via superávit comercial e na conta de serviços, devido a uma diminuição dos ganhos e dividendos remetidos ao exterior, e, na conta capital, incentivar o ingresso de investimentos estrangeiros para aproveitar a nova situação de competitividade. Desta forma, restabelecer-se-ia o equilíbrio na balança de pagamentos.

Antes de avançar mais, quero mencionar as alternativas que oferece a política cambial. Existem dois regimes cambiais extremos:

- tipo de câmbio flutuante;

- tipo de câmbio fixo, que, na sua versão mais extrema, a caixa de conversão, é o regime cambial que se utiliza na Argentina.

Por sua vez, dentro dos extremos, há um sem número de combinações possíveis.

Todas têm virtudes e defeitos, e a utilização de qualquer uma delas é matéria de debate entre os economistas há muito tempo.

Adicionalmente, há uma infinidade de supostos e restrições a serem introduzidos neles que complicam os modelos e oferecem diferentes respostas perante cada situação. Como este não é um texto sobre sistemas cambiais, vou correr o risco de realizar uma simplificação das diferentes teorias.

O tipo de câmbio flutuante apresenta as seguintes vantagens:

- os ajustes na balança de pagamentos são contínuos, pequenos e leves no caso de desequilíbrios macroeconômicos fundamentais;

- para gerar um ajuste na balança de pagamentos, só é necessário que varie o tipo de câmbio e não todos os preços internos da economia;

- quando o tipo de câmbio encontra-se em equilíbrio ou perto deste, a vantagem comparativa do país é evidente e seu padrão de comércio não se distorce;

- libera os países do uso da política monetária para atingir o equilíbrio externo, o que permite diminuir a taxa de juros e potencializar a taxa de crescimento; 
- permite que cada país se situe no ponto desejado da curva de Phillips, trade-off entre inflação e desemprego;

- evita os custos de intervenção no mercado de câmbio e os riscos de se cometer erros com respeito ao verdadeiro tipo de câmbio de equilíbrio.

Por sua vez, o tipo de câmbio fixo apresenta as seguintes vantagens:

- menor grau de incerteza no comércio e nas finanças internacionais;

- na ausência de grandes desequilíbrios macroeconômicos, é provável que conduza a um nível de especulação estabilizadora;

- exige uma maior disciplina nos preços, ou seja, gera menos inflação.

Como se pode observar, ambos apresentam vantagens e dificuldades e é muito difícil determinar qual é o sistema ideal para um determinado país. Mas, obviamente, qualquer política utilizada exige consistência entre as políticas fiscais, monetárias e cambiais, sendo na verdade o tipo de câmbio e o regime cambial utilizado uma conseqüência das duas primeiras. No fundo, a paridade das nossas moedas contra o dólar é um termômetro daquela consistência.

Por que o Brasil desvalorizou?

Limitar-me-ei a rever brevemente algumas circunstâncias dos últimos anos que desencadearam a desvalorização de janeiro.

O Plano Real iniciou-se em um contexto de uma enorme liquidez internacional e um renovado interesse pelos países emergentes perante os relativamente baixos rendimentos dos investimentos nos países desenvolvidos, unido a um processo de abertura econômica e reformas estruturais nessas economias que, teoricamente, tendia a situá-las em posição de crescer a taxas muito superiores às das economias maduras.

A autoridade econômica considerou que a abundância de liquidez teria suficiente duração para financiar a transição de um regime inflacionário para outro de estabilidade monetária. Isto requeria um processo de reforma do Estado e um programa de privatizações que permitiria a passagem do déficit causado pela falta de arrecadação do imposto inflacionário a uma situação na qual o orçamento se equilibrasse mediante ingressos genuínos.

Por motivos políticos, que, muito provavelmente, já são amplamente conhecidos, mas alguns dos quais permito-me enumerar: demoras nas privatizações, reconhecimento de passivos ocultos e, acima de tudo, restrições e rigidez econômica derivadas da própria Constituição, assim como a forte autonomia de que gozam os estados brasileiros, não foi possível atingir o equilíbrio orçamentário no setor público consolidado.

Se isto tivesse sido atingido, ter-se-ia também conseguido converter o tipo de câmbio vigente no início do Plano Real em um tipo de câmbio próximo ao de "equilíbrio" de longo prazo. Também deve levar-se em consideração que, a partir de 1995, com a desvalorização mexicana, o chamado "efeito tequila", as condições de liquidez vigentes nos mercados internacionais de capitais começaram a mudar, 
observando-se uma tendência à diminuição nos fluxos de investimento de curto e longo prazos colocados à disposição das assim chamadas economias emergentes.

$\mathrm{O}$ reconhecimento destes fatos motivou o Governo brasileiro a aplicar, gradualmente, uma política de minidesvalorizações, que permitisse compensar, no tempo, os efeitos da sobrevalorização da moeda.

A crise asiática, que começou em julho de 1997, provocou uma súbita contração dos fluxos de capital, que derivou em uma crescente perda de reservas. Para evitá-la, o Governo lançou um pacote de medidas fiscais e aumentou fortemente a taxa de juros em um cenário em que as contas públicas brasileiras registravam uma paulatina deterioração.

Deve-se destacar que a situação das contas externas dos países emergentes, medida como déficit da conta corrente do balanço de pagamentos relativo ao PIB, transformou-se em um dos indicadores mais relevantes observados pelos analistas do "risco país".

Se bem que se haja conseguido deter a queda nas reservas, pagou-se um alto preço: um importante aumento na dívida líquida do setor público, já que, na ausência de superávits fiscais que o compensem, o aumento na taxa de juros aumenta o déficit nominal, o que é compensado com maiores níveis de endividamento.

Unidas à deterioração da relação antes mencionada, começaram a aparecer algumas preocupações sobre a solvência de longo prazo do setor público brasileiro. Se bem que se haja conseguido um forte incremento nas reservas do Banco Central durante o primeiro semestre de 1998, isto deveu-se, de forma quase exclusiva, ao ingresso de capitais de curto prazo que aproveitavam diferenciais entre as taxas de juros externa e interna.

$\mathrm{O}$ default russo, em agosto do ano passado, gerou um consenso quase unânime entre os analistas de que o Brasil seria o próximo país a ter problemas de financiamento. Independentemente da existência ou não de fundamentos para esta consideração, este consenso levou a uma importante queda nas reservas internacionais que, para ser detida, obrigou, entre setembro e novembro, à aplicação de um conjunto de medidas fiscais e outro importante aumento na taxa de juros básica da economia, junto com a assinatura de um acordo com o FMI para restabelecer a credibilidade na política econômica.

A derrota no Congresso, no início de dezembro, de algumas das medidas fiscais propostas, junto com a moratória declarada pelo estado de Minas Gerais, no início de janeiro, geraram uma nova crise de confiança que tornou inevitável a desvalorização da moeda.

$\mathrm{O}$ acontecido desde aquele momento é história bem conhecida por todos. Mas, não quero deixar de mencionar algumas conseqüências estreitamente vinculadas que têm relação com as tendências futuras do comércio bilateral: 
- Primeiro, o escasso impacto sobre preços ao consumidor que teve uma desvalorização nominal de $60 \%$. Existe um grau de consenso importante a respeito de que o tipo de câmbio encontrava-se sobrevalorizado, mas somente entre 15 e $25 \%$.

- Segundo, a forte queda dos preços internacionais das commodities que se observava desde o final de 1997.

- Terceiro, os pobres resultados obtidos até o momento em termos de melhoria dos saldos da balança comercial, que de uma projeção inicial de superávit de 11 bilhões de dólares passou, em 7 meses, para uma projeção de déficit de 1 bilhão de dólares.

Para terminar este ponto, quero tecer algumas considerações que nos remetem ao que comentamos quando falamos dos diferentes regimes cambiais.

Primeira: a existência de déficits públicos de grande porte, caso Brasil, assim como o baixo grau de supervisão do sistema financeiro, caso Tailândia, criam condições ideais para a existência de crises de balança de pagamentos que conduzem a uma modificação do tipo de câmbio sob qualquer regime cambial.

Segunda: nenhum governo desvaloriza porque quer, já que uma desvalorização implica uma queda do poder de compra dos cidadãos e em uma redistribuição de recursos em favor dos produtores de bens comerciáveis internacionalmente através de mudanças no conjunto de preços relativos da economia.

Terceira: não necessariamente esta mudança tem resultados imediatos no comportamento da balança de pagamentos. Isto é conhecido no mudo dos economistas como efeito "J", pelo qual, no primeiro momento, o que se registra é uma piora das contas do setor externo e só posteriormente, com uma demora estimada entre 6 meses e um ano, começa-se a ver mudanças na composição desses fluxos. Isto pressupõe, desde já, que a inflação não erodiu o aumento no tipo de câmbio real. Adicionalmente, deve levar-se em consideração outros elementos como a composição das exportações e das importações, o contexto da economia internacional e o preço dos bens primários, no caso de serem estes uma proporção substancial dos fluxos de comércio.

\section{O comércio bilateral do 1991 à 1998}

A assinatura do Tratado de Assunção em março de 1991 deu lugar à definição de uma tarifa externa comum para cada uma das posições da nomenclatura tarifária e a um cronograma de redução de tarifas intrazona generalizado, a fim de levar a tarifa intrazona a zero no período de 4 anos, para mais de $90 \%$ das posições tarifárias. O pequeno restante, que divergia em tamanho, segundo cada um dos sócios, deveria transformar-se em zero em um período de quatro anos para o Brasil e a Argentina e de cinco anos para o Uruguai e o Paraguai. 
De forma simultânea com a assinatura desse tratado, todos os países membros começaram um processo de abertura de suas economias a fim de melhorar a eficiência relativa dos seus setores produtivos. Isto levou a aumentar de forma sensível o coeficiente de abertura da economia, especialmente desde o ponto de vista das importações, e traduziu-se em mudanças significativas no componente de valor agregado nacional, particularmente da produção industrial.

Os fluxos de comércio bilateral, afetados por esses fatores, começaram a experimentar uma evolução substantiva, tanto desde o ponto de vista quantitativo como qualitativo. Com relação a este último, deve destacar-se que os dois países transformaram-se nos respectivos principais clientes dos produtos manufaturados de maior valor agregado.

Uma parte importante do crescimento do comércio bilateral produziu-se por efeito das reduções tarifárias, o que implica tanto desvio quanto criação de comércio.

Outro efeito, a meu ver maior, se se exclui automóveis e petróleo, produziuse por efeito do crescimento das respectivas economias.

Existiu, também, um efeito tipo de câmbio, que favoreceu, em diferentes momentos, as exportações de ambos os países.

Adicionalmente, pode-se analisar a relação preços no varejo / preços no atacado, que serve como um "proxy" do nível de valorização do tipo de câmbio. Analisando o comportamento desses índices nos dois países, observa-se que o hiato entre os índices comparados de ambos tende a minimizar-se entre outubro de 95 e abril de 97 , o que se relaciona com as maiores taxas de crescimento das exportações argentinas e os maiores saldos favoráveis de balança comercial.

Cabe assinalar que, no caso argentino, o crescimento dessa relação no último ano é produto da forte deflação registrada em preços atacadistas, frente a uma inflação próxima de zero em varejistas. Enquanto que, no Brasil, a mudança na curva se produz pelo forte incremento nos preços atacadistas em relação aos varejistas, produto da desvalorização do real.

Provavelmente, no caso das exportações brasileiras com destino à Argentina, cuja taxa de crescimento foi maior que a do total de exportações brasileiras ao mundo desde 1991, prevaleceu um efeito de desvio de comércio e as maiores taxas de crescimento da economia argentina relativas às brasileiras. Devo salientar, neste sentido, que um estudo realizado no Centro de Economia Internacional da Chancelaria argentina mostrou que, no caso argentino, o Mercosul produziu um efeito de criação de comércio superior ao de desvio de comércio.

Porém, o contexto de crescimento econômico conjunto prevalecente desde 1995 mudou a partir do segundo semestre de 1998 com a crise russa. Ambas as economias começaram a deslizar rumo a uma recessão como o demonstram as menores taxas de crescimento do comércio bilateral. 
Devo registrar, nesse sentido, que as exportações argentinas com destino ao Brasil em 1998 caíram em valores absolutos, enquanto que as brasileiras mantiveram-se estáveis.

\section{O comércio bilateral depois da desvalorização}

A desvalorização real da moeda brasileira medida pelos diferentes tipos de índices é de grande magnitude. Supondo uma base 100 no mês de dezembro do ano passado, no mês de setembro a desvalorização do real com relação aos preços ao consumidor foi de cinqüenta por cento, com relação ao índice que combina os preços ao consumidor e ao atacado, foi de quarenta por cento, e, com relação aos preços no atacado, foi de trinta e três por cento.

Seu impacto no Produto Interno Bruto medido em dólares reflete-se na queda estimada entre 1999 e 1998.

Esta queda afeta o poder de compra da população brasileira, medida em termos de produtos importados, onde o efeito da desvalorização reflete-se integralmente, exceto onde a cadeia, até chegar ao consumidor, absorveu parte do aumento, e de produtos nacionais que têm na sua composição insumos importados, onde esse impacto reflete-se de forma mais parcial. Sirvam como exemplo disto insumos do setor agropecuário tais como os defensivos agrícolas.

Outro efeito que deve ser levado em consideração é que, ao reduzir o custo dos salários medidos em moeda estrangeira, outorgou-se uma melhora competitiva a toda exportação brasileira na qual a mão-de-obra fosse um insumo relevante.

Porém, nem todos os efeitos da desvalorização são benéficos para o setor produtivo. Quem estava endividado em moeda estrangeira sem cobertura, produto de créditos para capital de giro, financiamento de importações ou investimentos em bens de capital, enfrenta hoje o peso de maiores custos financeiros, que poderiam, no limite, até inverter o efeito positivo da desvalorização.

Por um conjunto de circunstâncias sobre as quais o Brasil não tem responsabilidade, tais como a queda nos preços dos principais bens primários exportados e a recessão nos seus principais sócios comerciais a quem vende bens manufaturados, os efeitos da desvalorização traduziram-se em uma forte queda nos fluxos de comércio exterior brasileiro com o mundo e com muito maior intensidade com a Argentina, que ingressou no mesmo período em uma forte recessão.

Como comentei antes, os dois elementos determinantes dos fluxos de comércio entre ambos os países são, dada a tarifa zero que vigora no Mercosul, o nível de atividade da economia e o tipo de câmbio real.

As projeções oficiais em ambos os países prevêem uma importante recuperação nos níveis de atividade econômica. No caso Argentino, calcula-se 
passar de uma queda do PIB estimada em 3,5\% em 1999 a um crescimento da ordem de $1 / 1,5 \%$ do PIB em 2000. No Brasil, as estimativas oscilam entre 2,5 e $4 \%$ de crescimento para o ano próximo, com uma estabilização dos valores do tipo de câmbio nominal. Em ambos os casos, espera-se que o setor mais dinâmico seja a indústria, que é o setor onde mais se sentiu o impacto recessivo. Adicionalmente, espera-se uma certa recuperação no preço das commodities, que, em alguma medida, se está começando a observar.

Que o setor industrial seja o mais dinâmico tem implicações relevantes desde o ponto de vista do comércio bilateral. No caso do Brasil, existem alguns estudos $^{2}$ que estimaram a elasticidade das importações frente a seus principais determinantes como o crescimento do produto industrial, o tipo de câmbio real e as tarifas, assim como também a elasticidade das exportações frente ao crescimento do comércio mundial, o tipo de câmbio real e o preço das commodities.

Se analisamos para o ano 2000 o comércio brasileiro com o mundo, dado o suposto crescimento do PIB de $4 \%$, é possível supor que, em um contexto onde o tipo de câmbio real tenda a valorizar-se, o resultado mais provável será o de uma balança comercial equilibrada.

Quando digo que o tipo de câmbio real tenderá a valorizar-se, estou pensando que o índice de preços relevante para os bens comerciáveis internacionalmente é o de preços no atacado, e que não é sustentável, no médio prazo, uma desvalorização da magnitude observada sem que esta impacte nesses preços atacadistas.

Existem outros estudos ${ }^{3}$ que estimam que o tipo de câmbio de equilíbrio necessário para alcançar um superávit na conta corrente do balanço de pagamentos da ordem de $4 \%$ encontrava-se, a preços de junho, perto de 1,60 real por dólar.

Dado este contexto, vou tentar prognosticar os resultados do comércio bilateral para o ano próximo.

As exportações argentinas beneficiar-se-ão do aumento dos preços de dois produtos importantes: trigo e petróleo.

Existem outros produtos nos quais o Brasil é deficitário e que a Argentina exporta, que também se verão beneficiados, como o algodão, o milho, o feijão e o arroz.

A previsível recuperação nos preços dos bens primários deveria ajudar à saída da recessão em que se encontra imersa a América Latina, permitindo uma leve recuperação em preços e volumes das exportações manufatureiras do Brasil.

Deve destacar-se que um elemento determinante dessa recuperação dependerá do comportamento do mercado automotor argentino. Por outro lado, um aumento nas exportações industriais, dados os coeficientes de abertura do setor, levarão também a um aumento nas importações de bens intermediários utilizados nos processos produtivos, ainda que seja factível que, no ano 2000, se 
possa observar algum efeito de substituição de importações como conseqüência de um incipiente processo de realocação de investimentos.

Com base nos saldos de balança desagregados por capítulo tarifário de todas as posições da nomenclatura comum do Mercosul, não é possível verificar grandes mudanças de tendência nos fluxos de comércio, comparando a evolução dos primeiros 8 meses de 1999 com os de 1998 e 1997, exceto em meia dúzia de capítulos dos quais o mais significativo é o dos calçados, capítulo 64, onde a Argentina passou de um superávit de 5,5 milhões de dólares a um déficit de 55,8 milhões de dólares entre 1997 e 1999, e em brinquedos, capítulo 95, onde se passa de um superávit de 5,2 milhões de dólares a um déficit de 1 milhão de dólares no mesmo período. Deve mencionar-se que os saldos positivos ou negativos de cada capítulo, sim, experimentam flutuações significativas.

Se excluímos o comércio de petróleo e automóveis por ter características especiais, já que, em um caso, incidiu a decisão política de que a Petrobras se abasteça na Argentina e, no outro, o comércio é administrado, o saldo de balança para a Argentina tende a zero ou é levemente negativo nos três períodos considerados.

Os recentes acordos entre as câmaras de calçado e papel, que autolimitam as exportações brasileiras até o ano próximo, unidas às prováveis reduções nas importações de determinados tipos de aço, produto de direitos antidumping ou uma autolimitação às vendas do Brasil, limitam o potencial de crescimento de alguns dos setores nos quais a indústria brasileira parecia ter possibilidades de ter um comportamento mais dinâmico, restando os capítulos 84 e 85, máquinas e aparelhos mecânicos e eletrônicos respectivamente, que poderiam ver-se, pelo menos a curto prazo, parcialmente afetados pelas novas disposições referentes à proteção ao consumidor.

A partir destes comentários, podemos presumir que as exportações argentinas de bens manufaturados e semimanufaturados responderão ao incremento de demanda, produto do crescimento da economia brasileira. Os produtos do setor agropecuário ver-se-ão favoravelmente afetados pelos resultados estimados da colheita brasileira, em particular no caso do arroz, do trigo e do milho.

No caso do petróleo, a combinação do desinteresse das companhias argentinas em vender este produto aos baixos preços vigentes durante 1998, unida à existência de outras prioridades políticas e comerciais brasileiras em relação à abertura de novos mercados, não permite esperar que se obtenham novamente saldos da magnitude registrada em 1997. Porém, deve mencionar-se que é provável que, para o final do ano 2000, entrem em funcionamento os gasodutos que proverão gás aos estados das regiões sul e sudeste, assim como compras de energia elétrica, que deveriam ajudar a aumentar os saldos estruturalmente favoráveis para a Argentina do capítulo 27. 
No caso dos automóveis, a exigência de paridade nos volumes exportados em dólares, unida à existência de acordos anteriores que reconheciam defasagens nos volumes exportados, permite inferir que se manterá o saldo positivo na balança comercial. O número final dependerá das condições de mercado interno de cada país e, no caso do Brasil, da possível implementação de um plan canje que dinamize as vendas ao mercado interno.

Deve levar-se em consideração que as quedas nos fluxos de comércio dos dois produtos mencionados, petróleo e automóveis, representa perto de $65 \%$ da queda total do comércio bilateral durante os primeiros oito meses de 1999.

Em resumo, excluídos os carros e o petróleo, e na ausência de variações significativas nos preços das commodities, não pode aguardar-se grandes mudanças nas cifras de comércio bilateral, podendo-se prever um aumento, não muito significativo, nas correntes de comércio e a manutenção de um saldo levemente superavitário para a Argentina.

Com o que foi dito, tentei analisar as conseqüências quantitativas da desvalorização do real no comércio bilateral.

Existem, porém, outros tipos de conseqüências, que eu considero positivas, e cujo horizonte de ação estende-se para além do ano 2000:

- Primeiro, a aceleração das negociações para o reconhecimento mútuo de certificados e equivalências para produtos industriais, alimentos e da área de saúde. Isto contribuirá a facilitar o acesso aos mercados respectivos de produtos que sofrem travas por dificuldades para obter certificados ou registros.

- Segundo, produziu-se um fortalecimento institucional do Mercosul através da maior utilização do Protocolo de Solução de Controvérsias.

- E, terceiro, acima de tudo, a crise mostrou a necessidade de se avançar, aceleradamente, na coordenação macroeconômica. Não sabemos quanto tempo requererá, mas se nós planejamos, como um objetivo, a união monetária, haverá três condições que serão necessárias cumprir para se ter uma moeda única:

- garantias de uma conversibilidade total e irrestrita entre as moedas dos sócios;

- liberalização completa dos movimentos de capitais e integração definitiva dos mercados bancários e financeiros;

- eliminação das margens de flutuação e fixação irrevogável das paridades monetárias.

Todos estes objetivos, que marcam o caminho do aprofundamento do Mercosul, implicam necessariamente que os governos aceitem a flexibilização progressiva dos antigos princípios da soberania nacional absoluta. Quanto antes comece este debate, melhor. 


\section{Notas}

1 Ernesto R. Seeslovsky,'Integración económica y armonización de políticas monetarias: un enfoque para el Mercosur", em El Mercosur en el Siglo XXI. Ediciones Ciudad Argentina, 1998.

2 Affonso Celso Pastore \& Associados: Is a DOLARES 11 billion trade surplus feasible. April, 1999.

3 Aumara Bastos Feu Alvim, E\&E, Ano III, No 15, Julho/Agosto, 1999.

Resumo

O texto analisa os impactos da desvalorização do real sobre o comércio bilateral Argentina-Brasil e, também, sobre o Mercosul. Ademais, aborda também questões relativas a perspectivas futuras desse comércio.

\section{Abstract}

The article analyses the impact of Real's devaluation on Argentina-Brazil bilateral trade and on Mercosur. Moreover, it also approaches issues related to the future of the above mentioned trade.

Palavras-chave: Argentina. Brasil. Política cambial. Desvalorização do real. Key-words: Argentina. Brazil. Exchange rate policy. Real's devaluation. 